\title{
Container maritime transport on an international scale: a procedure for aggregate estimation of demand variables
}

\author{
F. Russo \& G. Musolino \\ Università degli Studi Mediterranea di Reggio Calabria, \\ DIMET - Dipartimento di Informatica, Matematica, \\ Elettronica e Trasporti, Italy
}

\begin{abstract}
The paper presents a procedure for an aggregate estimation of demand variables of the containerized maritime freight market. The procedure is specified in different steps and a preliminary application is executed to forecast the throughput and transhipment variables in the Mediterranean area, according to expectations before the crisis and then to the new phenomena occurring today in the container market.

Keywords: containerized maritime freight, demand variables, Mediterranean area.
\end{abstract}

\section{Introduction}

In the scientific and technical literature, if variables of freight demand have been identified and measured [1], few variables have been associated to containerized maritime freight demand. They may be grouped into three main classes: throughput, transhipment and origin-destination (OD) flow. The first two classes of variables may be further characterized according to whether containers are full or empty. The third variable may provide a useful characterization in terms of empty containers if the problem of empty container management needs to be highlighted.

Throughput of a port derives from measurements of the number of containers handled by the (ship to shore) cranes per unit of time (e.g. TEUs/year); it is generally used for ex-post analysis. Throughput in the Mediterranean area is obtained as the sum of the throughput values in Mediterranean ports. 
Transhipment is obtained as the proportion of throughput related to containers that are subject to transhipment operations (e.g. TEUs/year). Transhipment in the Mediterranean area is obtained as the sum of transhipment values in Mediterranean ports. Containerized OD flows represent the amount of containerized freight travelling from a geographical area of origin to one of destination per unit time (e.g. TEUs/year).

In the containerized maritime freight market, where today all actors are dealing with the effects of the global economic crisis of years 2008-2010, there is a clear need to have a correct estimation of demand variables to support tactical and strategic decisions regarding the allocation of private and public resources. An important contribution is given by international consultants and research institutes, working in the field, providing general estimates concerning levels and trends referring to given macro-geographical areas and years. However, the lack of disaggregated data, not easy to obtain from the operators who prefer their activities not to be public, does not allow the same estimations to be obtained for more specific geographical areas and periods of interest. At the same time, historical available data (when provided by operators) for financial and commercial analysis and/or to monitor internal production processes (expost analysis) generally refer to those variables of the container maritime freight market connected to the use of port infrastructures, which are not clearly linked to trade-related variables. The latter variables are better suited to forecasting purposes (ex-ante analysis).

This paper aims to define a procedure to support:

- ex-post analysis for historical estimation at the disaggregate level, through estimation from heterogeneous data sources of demand variables of the containerized maritime freight market;

- ex-ante analysis for forecasting purposes, through the specification and calibration of relationships between the throughput and OD flow variables.

The procedure is specified in its different steps and a test application is executed to estimate the future trajectories of the demand variables for the Mediterranean area, according to expectations before the crisis and then to current developments in the container market.

This work is part of a two-year research project financed by the Italian Ministry of University and Research, whose general objective is to define guidelines for the competitiveness of the Italian transhipment ports of Gioia Tauro, Cagliari and Taranto in the euro-Mediterranean context. Other specific lines of research concern the development, and the application to the Mediterranean area, of models to estimate the demand variables of container maritime transport [2], of choice models of maritime container services and ports [3], of methods to evaluate the efficiency of container transhipment ports [4].

The following part of the paper is structured into three sections. Section 2 specifies the steps of the procedure that allows estimation of variables connected to containerized freight demand. Section 3 presents the results of the partial application of the procedure to the Mediterranean area. Section 4 reports the future work. 


\section{Proposed procedure}

The proposed procedure consists of different steps as presented in this section.

Step 0: initial vector of demand variables

Inputs are represented by a set of vectors of available data related to containerized maritime freight demand, $\left\{\underline{\mathbf{d}}_{t, s}\right\}$, referring to a set of time periods, $\{\mathrm{t}\}$, and geographical areas, $\{\mathrm{s}\}$. Each vector, $\underline{\mathbf{d}}_{\mathrm{t}, \mathrm{s}}$, is composed as follows:

$$
\underline{\mathbf{d}}_{t, s}=\left[\begin{array}{llll}
\underline{n}_{t, s} & \underline{\mathrm{m}}_{\mathrm{t}, \mathrm{s}} & \underline{\mathrm{f}}_{\mathrm{t}, \mathrm{s}} & \underline{\mathrm{e}}_{\mathrm{t}, \mathrm{s}}
\end{array}\right]^{\mathrm{T}}
$$

where

$\underline{\mathrm{n}}_{\mathrm{t}, \mathrm{s}}=\sum_{\mathrm{p} \in \mathrm{s}} \mathrm{n}_{\mathrm{t}, \mathrm{p}}$, throughput of geographical area s at time period $\mathrm{t}$, obtained as the sum of throughput of each container port $p$ belonging to the geographical area at time period $\mathrm{t}, \mathrm{n}_{\mathrm{t}, \mathrm{p}}$;

$\underline{\mathrm{m}}_{\mathrm{t}, \mathrm{s}}=\sum_{\mathrm{p} \in \mathrm{s}} \mathrm{m}_{\mathrm{t}, \mathrm{p}}$, transhipment of geographical area $\mathrm{s}$ at time period $\mathrm{t}$, obtained as the sum of transhipment of each container port $\mathrm{p}$ belonging to the geographical area at time period $\mathrm{t}, \mathrm{m}_{\mathrm{t}, \mathrm{p}}$ (transhipment is an aliquot of throughput, $\mathrm{n}_{\mathrm{t}, \mathrm{s}} \geq \mathrm{m}_{\mathrm{t}, \mathrm{s}}$ );

$\mathrm{f}_{t, \mathrm{~s}}=\Sigma_{\mathrm{o}} \mathrm{f}_{\mathrm{t}, \mathrm{o}-\mathrm{s}}+\sum_{\mathrm{d}} \mathrm{f}_{\mathrm{t}, \mathrm{s}-\mathrm{d}}$, OD flow of geographical area s at time period $\mathrm{t}$, obtained adding two terms:

- the sum over all geographical areas of origin, o, of OD flow between o and $\mathrm{s}, \Sigma_{\mathrm{o}} \mathrm{f}_{\mathrm{t}, \mathrm{o}-\mathrm{s}}$;

- and the sum over all geographical areas of destination, d, of OD flow between $\mathrm{s}$ and d, $\Sigma_{\mathrm{d}} \mathrm{f}_{\mathrm{t}, \mathrm{s}-\mathrm{d}}$;

$\underline{e}_{t, s}=\sum_{p \in s} e_{t, p}$, empty containers in geographical area s at time period $t$, obtained

as the sum of empty containers, as aliquot of throughput (and/or)

transhipment, handled in each port $\mathrm{p}$ belonging to the geographical area at time period $\mathrm{t}, \mathrm{e}_{\mathrm{t}, \mathrm{p}}$.

One or more values of the above variables, aggregated for geographical area s, may be unknown for the analyst, while disaggregated data at port level are generally not easily provided by terminal operators due to their direct financial and commercial implications.

Step 1: study area and reference time

The procedure starts defining the study area (spatial domain), $\mathrm{s}^{*}$, and reference period (time domain), $\mathrm{t}^{*}$. According to the nature of the analysis, which may be ex-post or ex-ante, $t^{*}$ may be respectively an historical or a future reference time period. The space-time domain $\left(\mathrm{s}^{*}, \mathrm{t}^{*}\right)$ has the following relationships with the available sets $\{\mathrm{s}\}$ and $\{\mathrm{t}\}$ :

- the study area, $\mathrm{s}^{*}$, may be coincident with, be part of, or partially overlapping with one or more available geographical areas belonging to the set $\{\mathrm{s}\}$

$$
\mathrm{s}^{*} \equiv \mathrm{s} \text { or } \mathrm{s}^{*} \subseteq \mathrm{s} \text { or } \mathrm{s}^{*} \cap \mathrm{s} \neq 0, \forall \mathrm{s} \in\{\mathrm{s}\}
$$

- the reference period, $t^{*}$, should belong to (or not be too distant from the extreme values, $t_{i}$ and $t_{k}$, of) the set, $\{t\}$, in order to allow estimation of direct 
and cross elasticities connected to finite variations of the above variables by means of the available data

$$
\mathrm{t}^{*} \equiv \mathrm{t} \text { or } \mathrm{t}^{*} \subseteq \mathrm{t} \text { or } \mathrm{t}^{*} \subseteq \mathrm{t}_{\mathrm{i}} \cup \mathrm{t}_{\mathrm{k}} \text { or } \mathrm{t}^{*} \cap \mathrm{t} \neq 0, \forall \mathrm{t}, \mathrm{t}_{\mathrm{i}}, \mathrm{t}_{\mathrm{k}} \in\{\mathrm{t}\}
$$

\section{Step 2: estimation of fitting parameters}

A set of models then allows to perform spatial and temporal fitting operations of the heterogeneous available input data to the given study area, $\mathrm{s}^{*}$, and reference period, $t^{*}$. The set of models may be grouped into two classes:

- temporal fitting models, which allow to fit the values of the demand variables belonging to the initial vector, $\underline{\mathrm{x}}_{\mathrm{t}, \mathrm{s}} \in \underline{\mathbf{d}}_{\mathrm{t}, \mathrm{s}}$, to the reference time period $\mathrm{t}^{*}, \mathrm{x}_{\mathrm{t}^{*}, \mathrm{~s}}$ :

$$
c_{t \rightarrow t^{*}, x}(\mathrm{f} \quad \text { for } \mathrm{x}=\mathrm{n}, \mathrm{m}, \mathrm{f}, \mathrm{e}
$$

- spatial fitting models, which allow to fit the values of the demand variables belonging to the initial vector, $\underline{\mathrm{x}}_{\mathrm{t}, \mathrm{s}} \in \underline{\mathbf{d}}_{\mathrm{t}, \mathrm{s}}$, to the study area $\mathrm{s}^{*}, \mathrm{x}_{\mathrm{t}, \mathrm{s}}$ :

$$
c_{s \rightarrow s^{*}, x}(\text { ) for } \mathrm{X}=\mathrm{n}, \mathrm{m}, \mathrm{f}, \mathrm{e}
$$

The models allow two vectors of parameters to be obtained:

- vector of temporal fitting parameters

$$
\mathbf{c}_{\mathbf{t}^{*}}=\left[\mathrm{c}_{\mathrm{t}^{*}, \mathrm{n}} \mathrm{c}_{\mathrm{t}^{*}, \mathrm{~m}} \mathrm{c}_{\mathrm{t}^{*}, \mathrm{f}} \mathrm{c}_{\mathrm{t}^{*}, \mathrm{e}}\right]^{\mathrm{T}}
$$

- vector of spatial fitting parameters

$$
\mathbf{c}_{\mathbf{s}^{*}}=\left[\begin{array}{llll}
\mathrm{c}_{\mathrm{s}^{*}, \mathrm{n}} & \mathrm{c}_{\mathrm{s}^{*}, \mathrm{~m}} & \mathrm{c}_{\mathrm{s}^{*}, \mathrm{f}} & \mathrm{c}_{\mathrm{s}^{*}, \mathrm{e}}
\end{array}\right]^{\mathrm{T}}
$$

\section{Step 3: final vector of demand variables}

The two above vectors feed a general model, together with the set of available input data, $\left\{\underline{\mathbf{d}}_{t, s}\right\}$, from which we can obtain as output a vector, $\underline{\mathbf{d}}_{t^{*}, s^{*}}$, of variables of containerized maritime freight demand for the given study area, $\mathrm{s}^{*}$, and reference period, $t^{*}$ :

$$
\mathbf{d}_{\mathrm{t}^{*}, \mathrm{~s}^{*}}=\boldsymbol{d}\left(\mathbf{c}_{\mathrm{t}^{*}}, \mathbf{c}_{\mathrm{s}^{*}},\left\{\underline{\mathbf{d}}_{\mathrm{t}, \mathrm{s}}\right\}\right)
$$

where:

$\mathbf{d}_{t^{*}, s^{*}}=\left[n_{t^{*}, s^{*}} m_{t^{*}, s^{*}} f_{t^{*}, s^{*}} e_{t^{*}, s^{*}}\right]^{\mathrm{T}}$;

$\boldsymbol{d}=[n() m() f() e()]^{\mathrm{T}}$ is the vector of functions related to each variable of containerized maritime freight demand.

Step 4: ratios between demand variables

Once vector $\mathbf{d}_{t^{*}, s^{*}}$ is estimated, it is possible to specify and calibrate models to express the mutual relationships among the variables of the above vector for the given study area, $\mathrm{s}^{*}$, and reference year, $\mathrm{t}^{*}$ (which are omitted in the notation):

- $c_{n, m}()$, throughput - transhipment model;

- $c_{n, f}()$, throughput - OD flow model;

- $c_{n, e}()$, throughput - empties model;

- $c_{m, e}()$, transhipment - transhipped empties model.

Due to the lack of data concerning one or more components of the initial vector of demand variables, $\underline{\mathbf{d}}_{\mathrm{t}, \mathrm{s}}$, Step 4 can be applied before Step 3; this means 
that one or more components of vector, $\mathbf{d}_{\mathrm{t}^{*}, \mathrm{~s}^{*}}$, can be estimated after estimating the ratio between two variables, whose aggregate values referred to the spacetime domain $\left(\mathrm{s}^{*}, \mathrm{t}^{*}\right)$ are known.

\section{Application in the Mediterranean area}

The procedure is applied to obtain an aggregate estimation of the demand variables of containerized maritime freight market at 2006 and 2015 for the Mediterranean area. This section presents the results of the partial application of the procedure: classification of available input data according to geographical areas and years; definition of the study area and reference period of time (year); estimation of variables of throughput and transhipment.

\subsection{Initial vector of demand, study area and reference period of time}

Input data are represented by values of throughput, transhipment, OD flows and empties with heterogeneous time references, $t$, and geographical areas, s, which are components of vectors belonging to the set, $\left\{\underline{\mathbf{d}}_{\mathrm{t}, \mathrm{s}}\right\}$.

They are made available from international research institutions working in the field, such as Ocean Shipping Consultants Ltd [5-7], Drewry Shipping Consultants Ltd [8-11], United Nations [12], Informa Business [13], reports from research projects [14-16], books [17, 18] and papers [19-21].

Available data are grouped into different spatial scales (Tab. 1): aggregate worldwide, aggregate euro-mediterranean (EU-Med), euro-mediterranean countries and ports; and time periods: historical or forecasted. A detailed description of available data are presented in [22].

Table 1: $\quad$ Initial vector of demand variables.

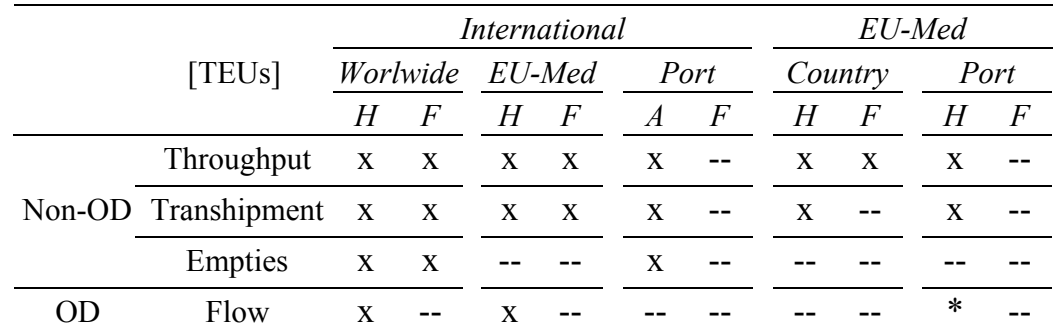

H, Historical; F, Forecasted; * available data for Gioia Tauro, Cagliari and Taranto; -- partially or completely unavailable.

The study area consists of countries facing the Mediterranean Sea, which may be considered as a homogeneous area $\left(\mathrm{s}^{*}=\mathrm{M}\right.$, Mediterranean area). It comprises:

Northern Mediterranean (NM) countries, including Spain, France, Italy, Malta, Greece, Turkey, Cyprus, Syria, Lebanon and Israel;

- Southern Mediterranean (SM) countries, including Morocco, Algeria, Tunisia, Egypt. 
The following countries (or parts of) were excluded from the study area:

- Atlantic (A) countries, facing the Atlantic such as Portugal, north-western Spain, Atlantic France, Canaries, Azores and Madeira;

- Black Sea (B) countries, facing the Black Sea such as Bulgaria, Romania, western Russia, Georgia.

The aim of the application is to estimate the variables of containerized maritime freight demand at 2006 and 2015, on the basis of scenarios defined before and after the global economic crisis of 2008-2010. Therefore, two reference years are defined: $t^{*}=2006$ and 2015; considering the trajectories as expected before, 2015-b, and after the crisis, 2015-a.

\subsection{Throughput estimation: fitting parameters}

The section presents the set of operations for the estimation of temporal and spatial fitting parameters and of throughput variable at 2006 and forecast at 2015 at the Mediterranean scale.

\section{Data at 2006}

Available data comprise the throughput values of Northern Mediterranean countries, including Atlantic countries ([8], [9]), $\underline{\mathrm{n}}_{04, \mathrm{NM}}=31.53$ mTEUs.

As the above value includes throughput related to countries facing the Atlantic, their throughput has to be estimated. The available throughput value for the above countries refers to 2004. Application of the temporal fitting model to 2006 provides the calibrated parameter, $\mathrm{c}_{06, \mathrm{~m}}$, as the average growth rate per year of throughput in the period 2000-2004. Application of the spatial fitting model allows the calibration of the parameter, $\mathrm{c}_{\mathrm{A}, \mathrm{m}}$, which is the aliquot of Atlantic countries throughput to subtract from the value of 31.53 mTEUs.

The throughput of Southern Mediterranean countries at 2006 is then estimated starting from the available throughput at 2004 for Morocco, Algeria, Tunisia, Egypt, Israel, Libya and Syria (data refer to this aggregation of countries), $\underline{\mathrm{n}}_{04, \mathrm{SM}}=3.72$ mTEUs.

Application of the temporal fitting model to 2006 allows calibration of the parameter, $\mathrm{c}_{06, \mathrm{~m}}$, as the average growth rate per year of throughput in the period 2000-2004, and execution of the temporal fitting for the above countries. By using calibrated temporal and spatial fitting parameters we can estimate the throughput in the Mediterranean area at 2006, $\mathrm{n}_{06, \mathrm{M}}=34.0 \mathrm{mTEUs}$.

\section{Scenarios at 2015}

Throughput forecasts at 2015 for the Mediterranean area were obtained considering the following scenarios:

- first case: scenario defined before the crisis according to [5];

- second case: scenario defined before the crisis according to $[8,9]$;

- third case: scenario defined after the crisis [11].

In the first case, the available data consist of the throughput values in the Mediterranean area (including Atlantic and Black Sea countries) at 2015 before 
the crisis in a baseline scenario (I), $\underline{\mathrm{n}}_{15, \mathrm{~b}-\mathrm{I}, \mathrm{M}}=91.64 \mathrm{mTEUs}$, and in a low one (II), $\underline{\mathrm{n}}_{15, \mathrm{~b}-\mathrm{II}, \mathrm{M}}=70.15$ mTEUs. Baseline and low scenarios depend on assumptions regarding worldwide economic growth, which may be respectively more or less accentuated (see [5]).

It is necessary to estimate the values of throughput related to Atlantic and Black Sea countries and subtract them from the above starting values. Availability of throughput forecasts at 2015 in baseline and low scenarios allow the calibration of spatial fitting parameters for the Atlantic countries. By using the calibrated spatial fitting parameters we can estimate throughput in the Mediterranean area at 2015 before the crisis for the low scenario, $\mathrm{n}_{15 \mathrm{~b}-\mathrm{II}, \mathrm{M}}=60.0$ mTEUs.

In the second case, the available data comprise the throughput of Northern Mediterranean countries, except for Syria, Lebanon and Israel, at 2013 (see [9]), $\underline{\mathrm{n}}_{13 \mathrm{~b}, \mathrm{NM}}=46.6 \mathrm{mTEUs}$. Application of the temporal fitting model to 2015 allows the calibration of parameter, $\mathrm{c}_{15 \mathrm{~b}, \mathrm{~m}}$, as the average growth rate per year of throughput in the period 2008-2013, obtaining a value of throughput, $\mathrm{n}_{15 \mathrm{~b}, \mathrm{NM}}=$ 50.9 mTEUs.

As Atlantic countries are included, the calibrated spatial fitting parameters respectively in the baseline and low scenarios allow us to estimate the aliquot of throughput related to these countries to subtract from $\mathrm{n}_{15 \mathrm{~b}, \mathrm{NM}}$. Moreover, the spatial fitting parameters related to Syria, Lebanon and Israel (S) countries respectively in the baseline and low scenarios are calibrated in order to estimate the aliquot of throughput related to these countries to add to $\mathrm{n}_{15 \mathrm{~b}, \mathrm{NM}}$.

The throughput of Southern Mediterranean countries at 2015 before the crisis in the baseline, $\mathrm{n}_{15 \mathrm{~b}-\mathrm{I}, \mathrm{SM}}=19.44$ mTEUs, and in the low scenario, $\mathrm{n}_{15 \mathrm{~b}-\mathrm{II}, \mathrm{SM}}=16.26$ mTEUs is forecasted in the same way as for 2006. The calibrated spatial fitting parameters allows, in this case, estimation of throughput in the Mediterranean area at 2015 before the crisis, $\mathrm{n}_{15 \mathrm{~b}, \mathrm{M}}=60.0$ mTEUs.

In the third case, the available data is the throughput of Northern Mediterranean countries at 2014 after the crisis (see [11]), $\underline{\mathrm{n}}_{14 \mathrm{a}, \mathrm{NM}}=36.76$ mTEUs. Application of the temporal fitting model to 2015 provides the calibrated parameter, $\mathrm{c}_{15, \mathrm{~m}}$, as the average growth rate per year of throughput during the period 2009-2015. Therefore, the forecasted value of throughput at 2015 after the crisis can be estimated, $\mathrm{n}_{15 \mathrm{a}, \mathrm{NM}}=38.4$ mTEUs, which is lower than the corresponding value before the crisis.

The above reduction is used to estimate the throughput at 2015 after the crisis of Atlantic countries and subtract it from the value of 38.4 mTEUs. The same considerations drive the estimation of throughput of Southern Mediterranean countries at 2015 after the crisis in the baseline scenario, $\mathrm{n}_{15 \mathrm{a}-\mathrm{I}, \mathrm{NM}}=14.65$ mTEUs, and in the low one, $\mathrm{n}_{15 \mathrm{a}-\mathrm{II}, \mathrm{NM}}=12.28$ mTEUs. By using the calibrated spatial and temporal fitting parameters we can estimate throughput in the Mediterranean area at 2015 after the crisis, $\mathrm{n}_{15 \mathrm{a}, \mathrm{M}}=46.0$ mTEUs.

\subsection{Transhipment estimation}

As there is a current lack of data on the transhipment variable, the procedure cannot be applied according to the sequence of steps described in section 3.2, as 
with the variable of throughput. Therefore, transhipment values, $\mathrm{m}_{06, \mathrm{M}}$ and $\mathrm{m}_{15, \mathrm{M}}$, are estimated by means of the model, $c_{m, n}($ ), inverting the sequence of steps three and four of the procedure.

\section{Data at 2006}

Available data concerns historical values of ratios between transhipment and throughput. Ratios on a period from 2005 to 2008 in Northern Mediterranean countries, including Atlantic Sea countries, are presented in [9]; values are stable and their average value is 0.43. Ratios between 1995 and 2015 in the Mediterranean area (Fig. 1) are provided by [6, 7]: average value between 2005 and 2008 is 0.365 , which is lower than the previous one. We refer to the more complete data from $[6,7]$, which presents both historical and forecasted ones. Application of the model, $c_{m, n}()$ yields a ratio at 2006 of $\mathrm{c}_{\mathrm{m}, \mathrm{n}}=0.365$.

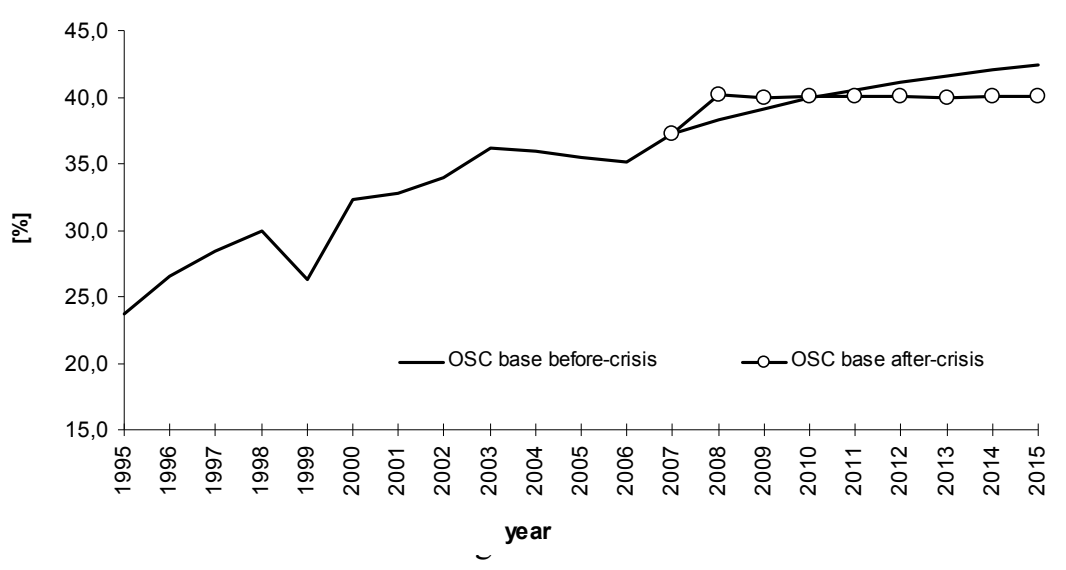

Figure 1: Historical and forecasted ratios between transhipment and throughput in the Mediterranean area: years 1995-2015 (source: $[6,7])$.

\section{Data at 2015}

According to $[6,7]$, the forecasted ratio between transhipment and throughput before the crisis increases from $37.2 \%$ at 2007 to $42.4 \%$ at 2015 , while after the crisis the ratio reaches $40.0 \%$ at 2008 and remain stable around this value until 2015 (see Fig. 1). Application of the model, $c_{m, n}($ ), with data at 2015 yields, before the crisis, ratios of $c_{m, n}=0.42$, and, after the crisis, of $c_{m, n}=0.40$.

\subsection{Preliminary results and future work}

The preliminary application of the procedure at Mediterranean scale $\left(\mathrm{s}^{*}=\mathrm{M}\right)$ allowed estimating throughput and transhipment variables at 2006 and 2015 before the crisis and after the crisis $\left(t^{*}=2006,2015-b, 2015-a\right)$. The results are presented in table 2. The values of transhipment variable for the Mediterranean 
area at 2006 and 2015 are estimated by means of the transhipment-throughput ratios, $\mathrm{c}_{\mathrm{m}, \mathrm{n}}$, obtained in section 3.3. At this stage of the application, the emptythroughput ratios, $\mathrm{c}_{\mathrm{e}, \mathrm{n}}$, for the Mediterranean area at 2006 and 2015 are assumed equal to the ones estimated at worldwide level: 0.21 at $\mathrm{t}^{*}=2006 ; 0.21$ at $\mathrm{t}^{*}=2015$ $\mathrm{b}$ and 0.23 at $\mathrm{t}^{*}=2015$-a (see [12]).

Table 2: Variables of throughput, transhipment and empties in the Mediterranean area (2006 and 2015).

\begin{tabular}{|c|c|c|c|c|c|c|}
\hline \multirow{3}{*}{ Throughput } & \multicolumn{2}{|c|}{$t^{*}=2006$} & \multicolumn{2}{|c|}{$t^{*}=2015-b$} & \multicolumn{2}{|c|}{$t^{*}=2015-a$} \\
\hline & \multicolumn{2}{|r|}{ [mTEUs] } & \multicolumn{2}{|c|}{ [mTEUs] } & \multicolumn{2}{|c|}{ [mTEUs]. } \\
\hline & $\mathrm{n}_{06, \mathrm{M}}$ & 34.0 & $\mathrm{n}_{15 \mathrm{~b}, \mathrm{M}}$ & 60.0 & $\mathrm{n}_{15 \mathrm{a}, \mathrm{M}}$ & 46.0 \\
\hline & $\mathrm{c}_{\mathrm{n}, \mathrm{m}}$ & 0.36 & & 0.42 & & 0.40 \\
\hline Transhipment & $\mathrm{m}_{06, \mathrm{M}}$ & 12.4 & $\mathrm{~m}_{15 \mathrm{~b}, \mathrm{M}}$ & 25.5 & $\mathrm{~m}_{15 \mathrm{a}, \mathrm{M}}$ & 18.4 \\
\hline & $\mathrm{c}_{\mathrm{e}, \mathrm{n}}$ & 0.21 & & 0.21 & & 0.23 \\
\hline Empties & $\mathrm{e}_{06, \mathrm{M}}$ & 7.1 & $\mathrm{e}_{15 \mathrm{~b}, \mathrm{M}}$ & 13.8 & $\mathrm{e}_{15 \mathrm{a}, \mathrm{M}}$ & 10.6 \\
\hline
\end{tabular}

$\mathrm{b}$, before the crisis, a, after the crisis.

The paper proposes a procedure for the estimation of demand variables of the containerized maritime freight market, with the aim to link the variables connected to the use of port infrastructures with the trade-related ones. The partial results of the application of the procedure at the Mediterranean area at 2006 and 2015 concern the variables of throughput and transhipment.

Future work will pursue two different lines: the first concerns the application of the procedure to the OD flow variable in order to estimate container flows between the Mediterranean area and other geographical areas of the rest of the world; the second concerns the estimation of demand variables at worldwide level in order to evaluate the role of the Mediterranean area in the worldwide containerized maritime freight market. Research perspectives concern the formulation of a unified model to simultaneously estimate temporal and spatial fitting parameters from available input data [23, 24].

\section{References}

[1] Bayliss B., The Measurement of Supply and Demand in Freight Transport. Avebury, Aldershot, England, 1988.

[2] Russo F. \& Assumma V., Container maritime transport at international scale: a model to simulate the demand flow in the Mediterranean basin. Proc. of Sustainable Development and Planning V, Brebbia C. A. (ed.), WIT Press, Southampton, Boston, 2011. ISBN 978-1-84564-544-1.

[3] Russo F., Chilà G. \& Iannò D., Container maritime transport at international scale: a model choice of service and hub port. Proc. of Sustainable Development and Planning V, Brebbia C. A. (ed.), WIT Press, Southampton, Boston, 2011. ISBN 978-1-84564-544-1.

[4] Russo F. \& Rindone C., Container maritime transport at international scale: Data Envelopment Analysis for transhipment ports. Proc. of Sustainable 
Development and Planning V, Brebbia C. A. (ed.), WIT Press, Southampton, Boston, 2011. ISBN 978-1-84564-544-1.

[5] Ocean Shipping Consultant Ltd, The European \& Mediterranean container port markets to 2015. United Kingdom, 2006.

[6] Ocean Shipping Consultant Ltd, Container Port Strategy. United Kingdom, 2007.

[7] Ocean Shipping Consultant Ltd, Container Terminal Management: a postcrisis perspective. United Kingdom, 2010.

[8] Drewry Shipping Consultant Ltd, Annual Review of Global Container Terminal Operators 2008. United Kingdom, 2008.

[9] Drewry Shipping Consultant Ltd, Annual Container Market Review and Forecast 2008-09. United Kingdom, 2008.

[10] Drewry Shipping Consultant Ltd, Annual Review of Global Container Terminal Operators 2008: Addendum. United Kingdom, 2009.

[11] Drewry Shipping Consultant Ltd, Container Forecaster 3Q09. United Kingdom, 2009.

[12] United Nations, Regional shipping and port development. Container traffic forecast 2007 update. Economic and social commission for Asia and the Pacific. New York, 2007.

[13] Informa Business, Containerisation International Yearbook 2009. United Kingdom, 2008.

[14] Crudo C., I flussi di merci nel porto di Gioia Tauro. Technical Report (in Italian). OSMETE Research project, 2006.

[15] FREEMED project, Transport demand analysis. New mobility scenarios in the FREE Trade Zone in the MEDiterranean basin. Deliverable 3, Interreg III B, Archimed, 2008.

[16] FREEMED project, Decision support system implementation. New mobility scenarios in the FREE Trade Zone in the MEDiterranean basin. Deliverable 3, Interreg III B, Archimed, 2008.

[17] Coronado D., Acosta M., del Mar Cerban M. \& del Pilar Lòpez M. (eds.) Economic Impact of the Container Traffic at the Port of Algeciras Bay. Springer-Verlag, Berlin, 2006.

[18] Meersman H., Van de Voorde E. \& Vanelslander T., (eds.). Future Challenges for the Port and Shipping Sector. INFORMA, London, 2009.

[19] Meersman H. \& van de Voorde E., The relationship between economic activity and freight transport. In Recent developments in transport modelling: lessons for the freight sector. Bingley, Emerald, 2008.

[20] Meersman H. \& van de Voorde E., Port management, operation and competition: a focus on North Europe. In The handbook of maritime economics and business. London, 2010.

[21] Medda F. \& Carbonaro G., Growth of Container Seaborne Traffic in the Mediterranean Basin: Outlook and Policy Implications for Port Development. Transport Reviews, 27: 5, Routledge, London, pp. 573-587, 2007. 
[22] Russo F., Gattuso D., Musolino G. \& Ferraro G., Domanda ed offerta nei porti container: fonti di riferimento e caratteristiche dei porti del Mediterraneo centrale. In I porti container italiani nel sistema EuroMediterraneo: dati di riferimento e stato dell'arte su modelli e metodi per l'analisi di domanda e offerta. F. Russo (ed), Franco Angeli, Milan, pp. 7190, 2010.

[23] Russo F. \& Vitetta A., Risk evaluation in a transportation system. In International Journal of Sustainable Development and Planning. Volume 1, Issue 2, 2006, Pages 170-191, 2006.

[24] Russo F. \& Vitetta A., Reverse assignment: calibrating link cost functions and updating demand from traffic counts and time measurements. In Inverse Problems in Science and Engineering, 2011, forthcoming. 